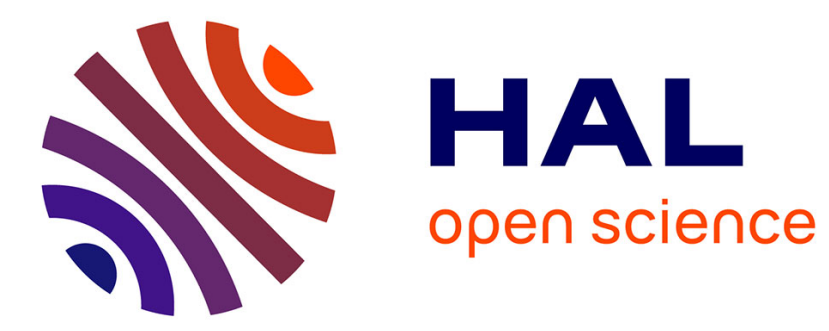

\title{
A QFN packaged grid array antenna in low dielectric constant LTCC for D-band applications
}

Camilla Kärnfelt, Bing Zhang, Herbert Zirath

\section{To cite this version:}

Camilla Kärnfelt, Bing Zhang, Herbert Zirath. A QFN packaged grid array antenna in low dielectric constant LTCC for D-band applications. IMWS-AMP 2016: IEEE MTT-S International Microwave Workshop Series on Advanced Materials and Processes for RF and THz Applications, Jul 2016, Chengdu, China. pp.1 - 4, 10.1109/IMWS-AMP.2016.7588410 . hal-01387606

\section{HAL Id: hal-01387606 https://hal.science/hal-01387606}

Submitted on 25 Oct 2016

HAL is a multi-disciplinary open access archive for the deposit and dissemination of scientific research documents, whether they are published or not. The documents may come from teaching and research institutions in France or abroad, or from public or private research centers.
L'archive ouverte pluridisciplinaire HAL, est destinée au dépôt et à la diffusion de documents scientifiques de niveau recherche, publiés ou non, émanant des établissements d'enseignement et de recherche français ou étrangers, des laboratoires publics ou privés. 


\title{
A QFN packaged grid array antenna in low dielectric constant LTCC for D-band applications
}

\author{
Camilla Kärnfelt ${ }^{*}$, Bing Zhang ${ }^{\dagger}$, and Herbert Zirath ${ }^{\S}$ \\ *Microwave Department, Lab-STICC UMR6285 \\ Institut Mines-Télécom, Télécom Bretagne, Brest, France \\ Email: Camilla.karnfelt@telecom-bretagne.eu \\ ${ }^{\dagger}$ Microwave Electronics Laboratory, Department of Microtechnology and Nanoscience, Chalmers \\ University of Technology, 41296 Göteborg, Sweden \\ Email: bzhang0609@hotmail.com \\ $\S$ Microwave Electronics Laboratory, Department of Microtechnology and Nanoscience, Chalmers \\ University of Technology, 41296 Göteborg, Sweden \\ Email: Herbert.zirath@chalmers.se
}

\begin{abstract}
A medium-gain Grid Array Antenna (GAA) is developed and manufactured in ESL41110, a low $\varepsilon_{r}$ Low Temperature Co-fired Ceramics (LTCC) from ElectroScience Laboratory. The antenna dimensions are $12 \mathrm{~mm} \times 12 \mathrm{~mm} \times 0.3$ mm and it has a measured impedance bandwidth from 135 to 142 GHz, with a boresight maximum gain of $7.96 \mathrm{dBi}$ and vertical beams. In order to realize this antenna, new LTCC fabrication steps had to be developed and qualified in the in-house procedure, including laser ablation of gold in the green state as well as after sintering.
\end{abstract}

Index Terms - D-band, Grid Array Antenna, Low Temperature Co-Fired Ceramics, LTCC, Quad Flat No-Lead Package, QFN.

\section{INTRODUCTION}

At the moment, the D-band frequency range 141 to 148 $\mathrm{GHz}$ is proposed for back-haul point-to-point relay stations and thus, several D-band Grid Array Antennas (GAA) have been developed and characterized for this purpose lately [1-6].

In some cases Liquid Cristal Polymer (LCP) is used [1] and in some cases Low temperature Co-fired Ceramics (LTCC) [26]. A cost benchmark on these two antennas has shown that, in small volume production, counting volumes of 500 antennas, the two solutions are very similar in cost. Comparing the two materials, LCP features low initial material cost, large processing area and is compatible with a low-cost process like wet etching. One of the drawbacks of LCP is its intrinsic softness which was resolved in [1] using a thick metal copper base of $0.5 \mathrm{~mm}$. However, with this choice followed the shortcoming of the feed-through via, which could not be plated through the whole structure while at the same time not thickening the transmission line pattern on either side of the structure (antenna GAA structure on one side and a coplanar waveguide probe launch at the other side). This problem is not encountered using LTCC since the via feed-through holes are realized in each layer for the number of layers needed. One is thus within the normal fabrication routine and no special treatment is needed.

When it comes to the LTCC materials for millimeter wave devises, the most common choice is to use A6M from Ferro $\left(\varepsilon_{\mathrm{r}}=5.75\right.$ and $\tan \delta<0.0023$ at $\left.145 \mathrm{GHz}\right)$ or $9 \mathrm{~K} 7$ from DuPont $\left(\varepsilon_{\mathrm{r}}=7.1\right.$ and $\tan \delta<0.0009$ at $\left.10 \mathrm{GHz}\right)$. These materials are low loss which is off course beneficial, however their relative permittivity is higher than for the ESL41110, which we have used here $\left(\varepsilon_{\mathrm{r}}=4.11\right.$ and $\tan \delta<0.006$ at $110-170 \mathrm{GHz}$ from our own measurements). A lower relative permittivity is advantageous to enhance the radiation of the antenna and to alleviate the line width and gap requirements as well as fabrication tolerances. However, the higher $\tan \delta$ will impact the losses for the antenna feeding structure but is, for a microstrip line, somewhat counterbalanced thanks to the larger required line width, and hence, decreased metallic losses.

This paper is organized as follows; chapter II gives an overview of the design of the antenna, chapter III presents the fabrication steps and newly developed processes for the manufacturing of the antenna module and the Quad Flat NoLead Package (QFN) package, chapter IV gives the measured results followed by a discussion and in chapter $\mathrm{V}$ we will conclude on this work.

\section{ANTENNA DESIGN}

Based on the in-house LTCC process, a QFN packaged Grid Array Antenna (GAA) is designed as shown in Fig. 1. The antenna is on the top of the package. The GAA module is flip chip mounted onto an LTCC QFN package, with a cavity to host an MMIC. Signal vias are routed through the two modules to the mother board. Thermal epoxy and vias in the 
QFN package, evacuates the heat from the chip back-side to the QFN heat sink. Thermal epoxy is also placed between the heat sink of the QFN package and the heat sink of the mother board. Fig. 2 shows the exploded view of the QFN package.
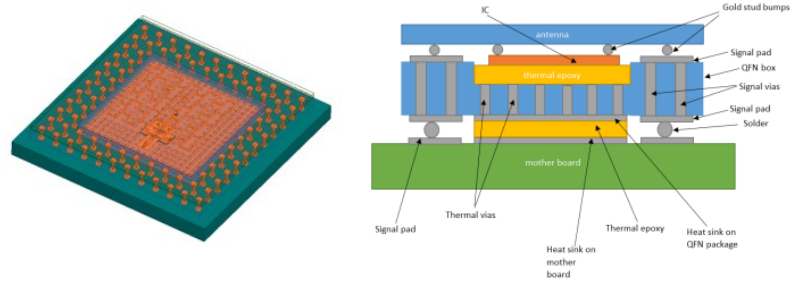

Fig.1. The QFN packaged GAA LTCC module overview: 3D view (left), cross section view (right).
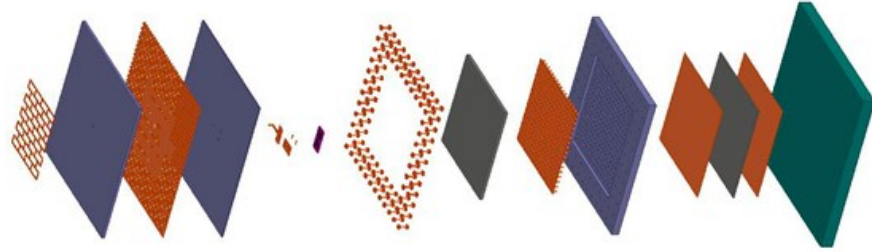

Fig.2. The exploded view of the QFN packaged GAA. The illustration is rotated $90^{\circ}$.

\section{FABRICATION STEPS AND SPECIAL PROCEDURES}

The GAA module, built on four layers of LTCC, is manufactured in-house at Télécom Bretagne using the tape ESL41110, ESL802 gold paste for via fill and ESL803 gold paste for conductor patterning. The tape comes in sheets of $100-130 \mu \mathrm{m}$ thickness and is compresses to $75 \mu \mathrm{m}$ after lamination and firing. The $\mathrm{x}$ - and $\mathrm{y}$-shrink is close to $15 \%$. Most fabrication procedure follows the standard LTCC steps as slanting, via hole and alignment hole cut out by laser, via fill, conductor screen printing, inspection, stacking, lamination, sintering and dicing. However, some special features were needed to process these antennas such as laser ablation of the gold on tape in green state and laser ablation of gold after sintering. The first ablation process was developed to enable a tight ground plane to via distance and the second ablation step in order to realize the small gap of $30 \mu \mathrm{m}$ needed for the coplanar measurement probe pads. The second ablation procedure was also described in [7] and proven to work up to $170 \mathrm{GHz}$ in [8].

The LTCC stack is shown in Fig. 3. where the different layers are named $L x$ with $x$ denotes the number from $L 1$ the bottom layer to $L n$ the top layer. In the same way, the conductor layers are named $L x_{-} C x$ and the via masks are named $L x \_V x$.

After slanting and laser cutting of the vias and alignment holes, the vias on $L 1 \_V 1, L 2 \_V 2, L 3 \_V 3$ and $L 4 \_V 4$ are filled. The same print mask is used for the vias on layer $L 1 V 1$ to $L 3 \_V 3$, while L4_V4 also includes additional vias to connect the Co-Planar Waveguide (CPW) grounds of the launch pad to the internal ground plane. Thereafter, the grid array is printed on the down side of $L 1$, thus named $L 1 \_C O$, since normally we print on the top side. The internal ground plane is printed as L3_C3 and the top feeding structure as $L 4 \_C 4$.
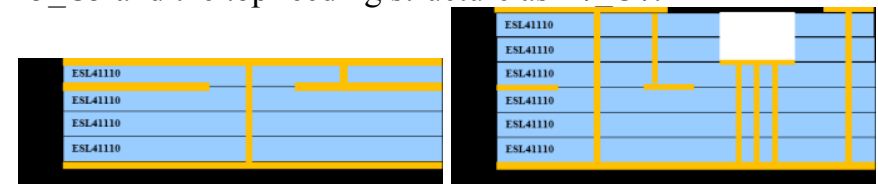

Fig.3. LTCC stack: GAA module (left) with antenna radiation pattern on the bottom of L1, QFN package (right).

After visual inspection the layers are stacked on an alignment fixture, sealed at the corners using Isopropanol, lifted off the alignment fixture and passed through a vacuum system to empty the air captured between layers and then stack is laminated in a uniaxial press at $+70^{\circ} \mathrm{C}$ for 10 minutes at a pressure of 220 bars. Finally the substrates are sintered in a static oven following the profile given by the manufacturer.

The QFN package was manufactured in the same way as the GAA module; however, six layers were used for the mechanical stability of the circuit, Fig. 3. Ball bump stud bonding was used to join the two parts by flip chip assembly.

The final result, before chip assembly and joining the modules, is shown in Fig. 4.

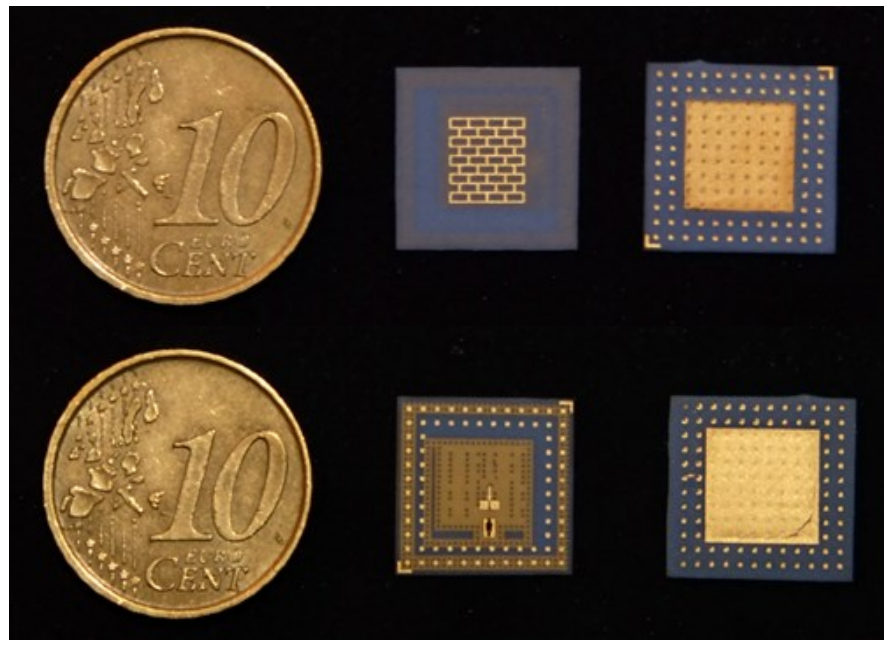

Fig.4. Final result of the GAA module (middle column) and QFN package (right column). The two sides are shown of the modules, no chip is assembled.

\section{A. Ablation of gold in green state tape}

The antenna is fed from the backside using a metallized 180 $\mu \mathrm{m}$ diameter via to pass the signal from the feeding side to a central point in the grid array on the radiation side. In order to fill the vias with gold paste, the screen mask is provided by a catch-pad of $230 \mu \mathrm{m}$. The signal feed via passes through all four layers of the structure and through the internal ground plane which is positioned of the third tape, c.f. Fig. 3. This 
ground plane serves as ground both for the antenna structure on that radiation side and to the micro-strip line on the feeding side of the structure. The ground plane is opened to not short circuit the signal feed via with a $400 \mu \mathrm{m}$ circular opening. The distance from the catch pad to the ground plane opening is thus only $85 \mu \mathrm{m}$. Unfortunately we experienced some overflow of the gold during screen printing and also a misalignment between screen printing of the layers, leaving us with the result seen in the micrograph of Fig. 5. Now, to fix this, we used a micromachining station, Astree 250 from Novalase, based on a $1064 \mathrm{~nm} \mathrm{Nd:YAG} \mathrm{laser.} \mathrm{The} \mathrm{DPSSL}$ laser "Aion Industrial-V" has a $25 \mu \mathrm{m}$ beam diameter which can be used to eliminate the short circuit. The laser is performing three traces, the first two distanced at $20 \mu \mathrm{m}$ apart with the following parameters: frequency $=40 \mathrm{kHz}$, Power $=3$ $\mathrm{W}$, displacement speed $\mathrm{v}=30 \mathrm{~mm} / \mathrm{s}$ and repeated three times descending into the tape with $3 \mu \mathrm{m}$ each time. These two traces will remove the printed gold. The third trace is centered between the former two, having somewhat different parameters: frequency $=20 \mathrm{kHz}$, Power $=4 \mathrm{~W}$, displacement speed $\mathrm{v}=30 \mathrm{~mm} / \mathrm{s}$ and one single passage. This trace cuts into the dielectric layer making sure no short circuit remains. This way the tape is valid for further fabrication. Fig. 5 shows the initial result after screen printing and drying with the short circuit and the results after laser ablation.
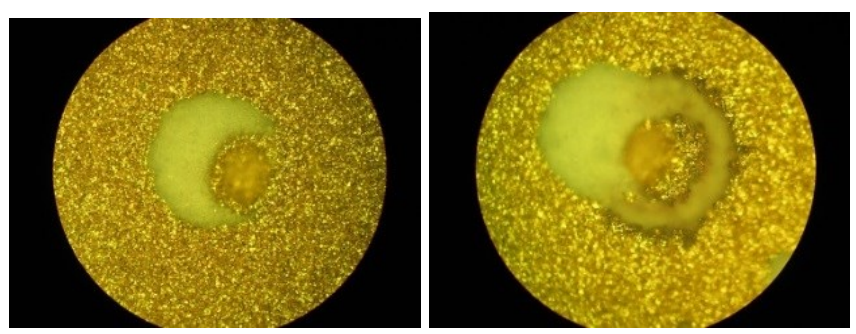

Fig.5. Micrographs of ground plane; short circuited to the via (left), ablation result (right).

\section{B. Ablation of gold after sintering}

The screen printing procedure rarely allows for a line width and gaps less than $50 \mu \mathrm{m}$. In order to measure this antenna at the D-band we intend to use a probe station and GSG probes with $100 \mu \mathrm{m}$ pitch from Piccoprobe. It is thus necessary to produce a coplanar probe pad with a small gap having a $50 \Omega$ characteristic impedance. With the laser ablation parametrized to frequency $=40 \mathrm{kHz}$, Power $=4 \mathrm{~W}$, displacement speed $\mathrm{v}=1$ $\mathrm{mm} / \mathrm{s}$ and repeated three times descending into the tape with 3 $\mu \mathrm{m}$ each time $25 \mu \mathrm{m}$ wide traces are made in the sintered gold on the top surface. The middle signal line is designed to be $100 \mu \mathrm{m}$, the gaps are $30 \mu \mathrm{m}$ leaving only $15 \mu \mathrm{m}$ distance from the gap to the placement of the ground probes on the two ground pads. Since the CPW pad is DC grounded by a metallized via we arrive at a characteristic impedance of $49 \Omega$ at $140 \mathrm{GHz}$. The laser ablated probe pad is placed on the feed side of the photograph in Fig. 6.

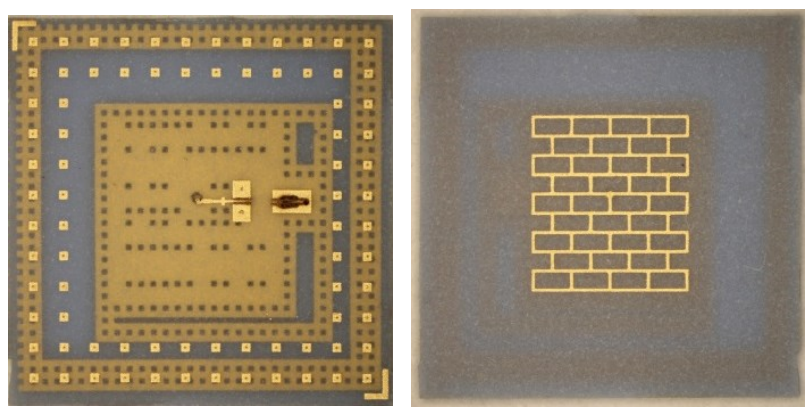

Fig.6. GAA antenna; feed side (left) and radiating side (right).

\section{ANTENNA MEASUREMENTS}

The antenna is measured in a far-field measurement setup at Karlsruhe Institute of Technology [9]. Fig. 7 shows the reflection parameter $\left|\mathrm{S}_{11}\right|$ of the antenna. The simulated impedance bandwidth is from $141-152 \mathrm{GHz}$; in measurement it ranges from $135-142 \mathrm{GHz}$. Fig. 8 describes the peak realized gain of the antenna. The maximum simulated gain is $9.25 \mathrm{dBi}$ at $146 \mathrm{GHz}$; while in measurement it is 7.96 $\mathrm{dBi}$ at $142 \mathrm{GHz}$. It has vertical beams on the boresight at 141 $\mathrm{GHz}$ as is shown in Fig. 9. The difference between the simulated and measured antenna performance can be accounted for by fabrication tolerances such a certain misalignment between substrate layers and not correct material characteristics during the simulation $\varepsilon_{\mathrm{r}}=4.18$ and $\tan \delta=0.018$ used instead of $\varepsilon_{\mathrm{r}}=4.11$ and $\tan \delta=0.006$ measured later on.

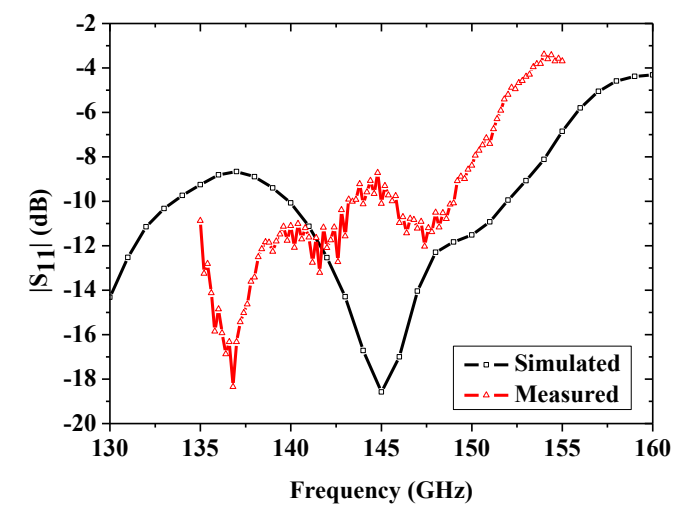

Fig.7. S11 of the antenna. 


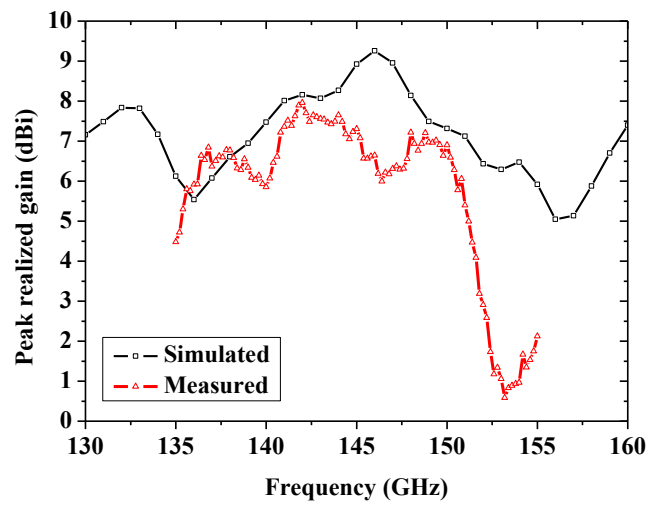

Fig.8. Peak realized gain of the antenna.

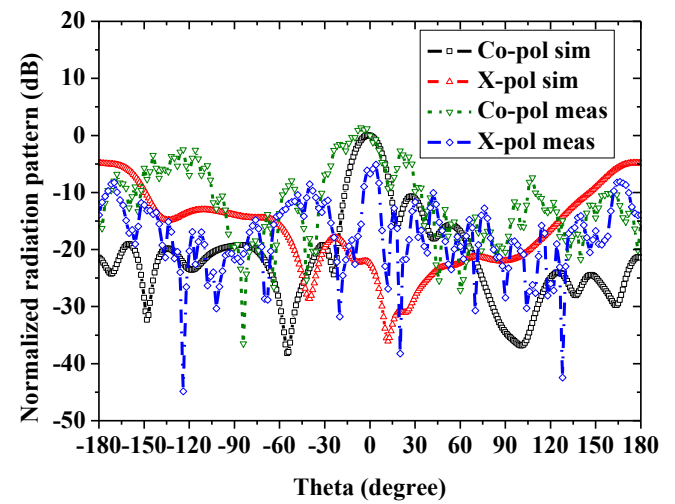

a)

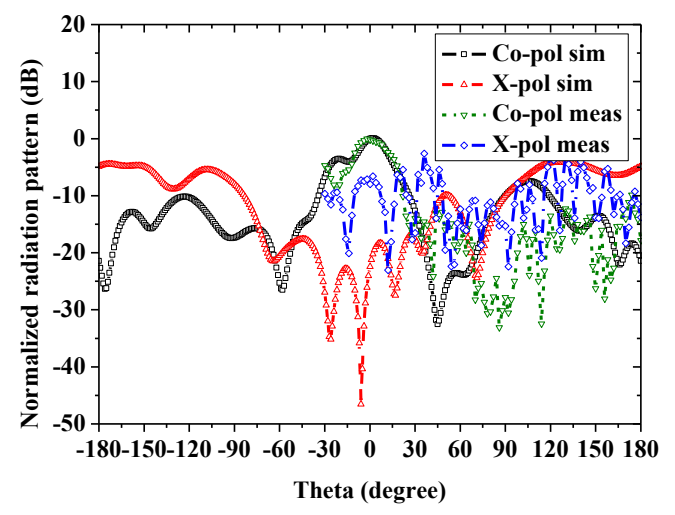

b)

Fig.9. Radiation patterns of the antenna at $141 \mathrm{GHz}$ : (a) phi $=0^{\circ}$ and (b) phi $=90^{\circ}$.

\section{CONCLUSION}

In this paper, we have designed and realized a D-band QFN packaged GAA by an in-house low dielectric constant LTCC process. The GAA module shows acceptable performance and agreement between simulation and measurement. A small misalignment may count for the difference between simulated and measured results as well as a difference in the material characteristics. Future work will focus on process improvement and a complete module with chip and heat-sinks.

\section{ACKNOWLEDGEMENT}

The authors would like to thank the scientific direction of Télécom Bretagne enabling the Visiting Scientist Program called 'Package antenna in LTCC technology for mm-wave single chip transceivers'; the Swedish Foundation for Strategic Research (SSF) through the program of 'RFIC solutions for very high data rate, energy and spectrum efficient wireless THz communication' and the Swedish Research Council (VR) through the program of 'Gigabits at $\mathrm{THz}$ frequencies'. The authors would also like to acknowledge Heiko Gulan and Thomas Zwick from Institute of Radio Frequency Engineering and Electronics, Karlsruhe Institute of Technology for the antenna measurement.

\section{REFERENCES}

[1] B. Zhang, C. Kärnfelt, H. Gulan, T. Zwick, and H. Zirath, "A Dband packaged antenna on organic substrate with high fault tolerance for mass production," IEEE Trans. Comp. Packag. Manuf. Technol., vol. 6, no. 3, pp. 359-365, Mar. 2015.

[2] B. Zhang, H. Gulan, T. Zwick, Y. Li, U. Oderfalt, F. Carlsson, and $\mathrm{H}$. Zirath, "Integration of a $140 \mathrm{GHz}$ packaged LTCC grid array antenna with an InP detector," IEEE Trans Comp. Packag. Manuf. Technol., vol. 5, no. 8, pp. 1060-1068, Aug. 2015.

[3] B. Zhang and Y. P. Zhang, "Analysis and synthesis of millimeter-wave microstrip grid array antennas," IEEE Antennas Propag. Mag., vol. 53, no. 6, pp. 42-55, Dec. 2011.

[4] B. Zhang and Y. P. Zhang, "Grid array antennas with subarrays and multiple feeds for $60-\mathrm{GHz}$ radios," IEEE Trans. Antennas Propag., vol. 60, no. 5, pp. 2270-2275, May 2012.

[5] B. Zhang, Y. P. Zhang, Diane Titz, Fabien Ferrero, and Cyril Luxey, "A circularly-polarized array antenna using linearlypolarized sub grid arrays for highly-integrated $60-\mathrm{GHz}$ radio," IEEE. Trans. Antennas Propag., vol. 61, no. 1, pp. 436-439, Jan. 2013.

[6] B. Zhang, D. Titz, F. Ferrero, C. Luxey, and Y. P. Zhang, "Integration of quadruple linearly-polarized microstrip grid array antennas for $60-\mathrm{GHz}$ antenna-in-package applications," IEEE Trans. Comp. Packag. Manuf. Technol., vol. 3, no. 8, pp. 1293-1300, Aug. 2013.

[7] C. Kärnfelt, P. Coant, M. Sinou, J.-P. Coupez, D. Bourreau, and A. Peden, "Grooved laminated waveguide devices for U-, V-, W-and G-band applications," in Microwave Conference (EuMC), 2015 European, 2015, pp. 777-780.

[8] C. Kärnfelt, P. Coant, M. Sinou, J.-P. Coupez, D. Bourreau, and A. Péden, "Grooved laminated waveguides in LTCC for $\mathrm{mm}-$ wave packaging," Micro/Nano-electronics Packaging and Assembly, Design and manufacturing Forum, (MiNaPAD2015), Grenoble, France, Apr., 2015.

[9] H. Gulan, S. Beer, S. Biebold, C. Rusch, A. Leuther, I. Kallfass, and T. Zwick, "Probe based antenna measurements up to 325 $\mathrm{GHz}$ for upcoming millimeter-wave applications," in Proc. IEEE Int. Workshop Antenna Technol. (iWAT2013), Karlsruhe, Germany, Mar. 4-6, 2013, pp. 228-231. 